\title{
APLIKASI MOBILE SQL UNTUK ADMINISTRASI BASISDATA POSTGRESQL MEMANFAATKAN JAVA SERVLET
}

\author{
Erick Costanio dan Hapnes Toba \\ Fakultas Teknologi Informasi, Universitas Kristen Maranatha \\ Jl. Prof. Drg. Suria Sumantri No. 65 Bandung 40164 \\ Email: costanio@gmail.com, hapnestoba@yahoo.com
}

\begin{abstract}
ABSTRAK: Mobile SQL adalah alat administrasi basisdata PostgreSQL berbasis mobile menggunakan koneksi HTTP. Teknologi mobile yang bersifat fleksibel membuat administrator dapat segera melakukan perawatan basisdata jika diperlukan tanpa harus berada di lokasi server. Pengembangan aplikasi menggunakan teknologi Java ME dan Servlet, serta dapat dijalankan menggunakan telepon seluler sebagai klien dengan spesifikasi MIDP 2.0, CLDC 1.1 dan GPRS yang telah diaktifkan, sedangkan untuk komputer server diperlukan web server dan DBMS. Fitur utama pada aplikasi ini antara lain: menjalankan perintah SQL, membuat tabel dan pengguna, melakukan backup dan recovery basisdata, menulis dan menjalankan bahasa prosedural SQL - PL/pgSQL, serta mengirim log melalui email. Aplikasi Mobile SQL dapat digunakan untuk melakukan administrasi basisdata menggunakan telepon seluler.
\end{abstract}

Kata kunci: Mobile SQL, Java ME, DBMS, administrasi basisdata

\begin{abstract}
Since a database administrator is not always be in a fix place, we need something that make it possible for the administrator to manage the database anywhere. A Mobile SQL technology is flexible enough for an administrator to do this maintenance job immediately, such as for query operation, and database recovery. Our goal is to develop such application using Java ME and Servlet technology, thus making it runs on every mobile device that has MIDP 2.0, CLDC 1.1, and GPRS enabled device. While on a server computer, it needs web server and a DBMS. For this purpose, an object-oriented DBMS Postgre has been choosen. The main features of this application are: executing SQL queries; creating tables and users; making database backup and recovery; creating and executing SQL procedural language - PL/pgSQL; and sending a log through email. This application will also notify another adminstrator through email for any changes that has been made in the database
\end{abstract}

Keywords: Mobile SQL, Java ME, Postgre, database administration, servlet

\section{PENDAHULUAN}

Pada era komputerisasi sekarang, hampir semua kegiatan dikerjakan menggunakan komputer sehingga penyimpanan data juga dilakukan secara komputerisasi. Oleh karena itu, diperlukan suatu sistem bernama Database Management System (DBMS) yang menangani data secara komputerisasi. DBMS merupakan kumpulan libraries, aplikasi dan utilitas yang membuat pengembang aplikasi tidak perlu mengkhawatirkan detail penyimpanan dan pengaturan data.

DBMS yang berisi banyak data memerlukan administrator basisdata untuk mengatur dan merawat kumpulan data tersebut. Namun sering kali seorang administrator basisdata kewalahan merawat basisdata karena faktor tempat dan waktu, contohnya: administrator basisdata menerima panggilan mendadak di malam hari, hanya untuk meng-update beberapa record dalam basisdata. Contoh lain, administrator basisdata sedang sibuk sehingga tidak dapat mem- backup data, sedangkan hari ini adalah waktu terakhir untuk backup.

Dari contoh permasalahan di atas, penulis mengusulkan suatu aplikasi pada telepon seluler (mobile application) untuk dapat membantu administrator basisdata menjalankan fungsinya. Dengan aplikasi semacam ini, administrator basisdata tidak harus selalu datang ke server untuk melakukan query, dan hal ini tentu akan menjaga berlangsungnya proses bisnis [2]. Administrator basisdata cukup membuka aplikasi pada telepon seluler dan mengirim query ke web server, kemudian Web server akan mengakses basisdata dan memberikan service untuk request yang diinginkan itu.

\section{ADMINISTRASI BASISDATA}

Administrasi basisdata merupakan kumpulan tugas-tugas yang dilakukan seorang administrator basisdata untuk merawat data, menjaga performance server basisdata, dan mengamankan basisdata [4]. 
Salah satu dari beberapa alasan utama menggunakan basisdata adalah untuk memiliki kontrol diantara data dan program yang mengakses data tersebut. Orang yang bertindak sebagai kontrol diantara data dan program dinamakan administrator basisdata. Fungsi utama seorang administrator basisdata antara lain adalah sebagai berikut :

- Administrator basisdata membuat bagan basisdata dengan menjalankan statement DDL.

- Membuat struktur penyimpanan dan mendefinisikan metode akses.

- Melakukan modifikasi bagan basisdata.

- Memberikan hak akses suatu data kepada user.

- Perawatan rutin seperti: melakukan backup basisdata, memastikan cukupnya tempat penyimpanan data, mengawasi tugas-tugas yang berjalan pada basisdata dan memastikan tidak terjadi penurunan performance.

\section{TEKNOLOGI JAVA ME}

Teknologi Java ME sangat tergantung pada perangkat yang digunakan, bisa dari kemampuan perangkat atau dari dukungan perangkat terhadap Java ME [1, 3]. Java ME merupakan bagian dari Java SE tapi tidak semua library java SE dapat digunakan pada java SE dan Java ME memiliki beberapa library khusus yang tidak dimiliki java SE.

Konfigurasi dan profile yang digunakan pada aplikasi adalah konfigurasi CLDC 1.1 (Connected Limited Device Configuration) dan profile MIDP 2.0 (Mobile Information Device Profile). CLDC merupakan spesifikasi dasar dari Java ME yang berupa kilobyte virtual machine, library dan API (Aplication Programming Interface). MIDP adalah spesifikasi untuk sebuah profil Java ME. MIDP membahas sesuatu yang lebih spesifik untuk sebuah perangkat misalnya kemampuan layar perangkat, memori, kemampuan multimedia, inputan perangkat. Untuk menulis MIDP diperlukan sebuah aplikasi yang dinamakan MIDlet. Sebagai bagian dari kelas java.micoedition.midlet. MIDlet hanya dapat dikembangkan untuk perangkat MIDP dan hanya dapat digunakan pada MIDP dan CLDC APIs.

MIDlet membuat, mengalokasikan dan menghapus beberapa tipe berbeda dari sumber berdasarkan waktu hidup, termasuk obyek, data dan threads. MIDlet membuat obyek yang dibutuhkan ketika dieksekusi, menghapus obyek yang sudah tidak dibutuhkan atau ketika MIDlet diberhentikan sementara atau dihancurkan. MIDlet membaca data dari tempat penyimpanan ketika startup dan menyimpan data ketika dimatikan. MIDlet menciptakan threads untuk melakukan tugas secara bersamaan dan menghentikan thread ketika waktunya tepat.

\section{HTTP SERVLET}

Hyper Text Transfer Protocol (HTTP) adalah protocol komunikasi yang diperlukan setiap perangkat MIDP untuk melakukan koneksi dan meminta informasi. HTTP membuat streaming yang membawa pesan antara HTTP Client dan web server dimana web server akan mengembalikan hasil request berupa dokumen dan responds code kepada client. Hal ini bekerja secara baik pada lingkungan desktop tapi tidak demikian pada perangkat MIDP. Tidak semua perangkat MIDP memiliki koneksi langsung ke Internet dan biasanya tidak mendukung socket. Perangkat MIDP juga tidak memiliki User Interface yang mendukung tampilan HTML.

Request dan responses memiliki dua bagian yaitu headers dan content. URL yang diketikkan pada web browser akan membuat sebuah HTTP request dan mengirimnya ke server. Server mencari file yang diminta dan mengirimkannya melalui HTTP response. Header dari response mendeskripsikan tentang beberapa hal seperti tipe web server, tipe file response, panjang dari file response, dan informasi lainnya. Isi dari response adalah data itu sendiri.

Servlet merupakan salah satu teknologi yang dapat mengolah respon yang bersifat dinamis melalui HTTP. Servlet dapat menangani beberapa protokol seperti FTP, SMTP, HTTP. Namun dalam praktiknya hanya server HTTP yang banyak dilayani, khususnya dengan class HttpServlet.

\section{PERANCANGAN APLIKASI}

\section{Fitur Aplikasi}

Mobile SQL dibuat untuk memungkinkan dilakukannya administrasi basisdata melalui telepon seluler, menghemat waktu administrator basisdata dalam melakukan perawatan, untuk dapat mengetahui perubahan basisdata yang terjadi melalui email, dan dapat menulis bahasa prosedural (Procedural Language). Fitur-fitur yang terdapat pada Mobile SQL yaitu:

1. Login

Fitur login diperlukan untuk otorisasi pengguna. Fitur login mencocokkan informasi pengguna yang ada pada server basisdata. Apabila informasi cocok maka pengguna akan diperbolehkan masuk aplikasi. Apabila gagal/tidak cocok maka pengguna tidak diperbolehkan masuk aplikasi.

2. Query Tool

Fitur ini memungkinkan administrator membuat, menyimpan dan menjalankan query. Terdapat tiga tipe SQL Command yang dapat dijalankan 
administrator [4]. Pertama adalah Data Manipulation Language (DML). Untuk "Select" Statement, pengembalian nilai akan ditampilkan pada tabel yang dibuat menggunakan Custom Item Java ME. Kedua adalah Data Definition Language (DDL). Pada DDL administrator dapat membuat tabel, melakukan perubahan dan menghapus struktur data dari tabel. Ketiga adalah Data Control Language (DCL). Pada DCL administrator dapat memberikan, membatasi atau menghapus hak akses user terhadap basisdata. Hak Akses yang diberikan dapat berupa Read Only, Update, Delete, Add, dan untuk manipulasi struktur basisdata seperti atribut, tabel, indeks.

3. Query Manager

Fitur ini dilengkapi dengan GUI untuk memberi kemudahan bagi administrator dalam mendefinisikan, memanipulasi, dan mendapatkan data. Query
Manager memiliki beberapa fungsi seperti membuat, modifikasi atau menghapus tabel/login role/group role. Melihat deskripsi tabel. Membuat foreign key dan indexes pada tabel. Merubah struktur tabel pada basisdata.

4. Procedural Editor

Fitur ini membantu administrator dalam menulis bahasa prosedural yang dipakai oleh sebuah DBMS sehingga administrator dapat melihat dan menggunakan kode fungsi seperti berikut [4]:

- Operator seperti [], -, ^, AND, OR

- Built in Function seperti SysDate, SUM, AVG, TO_DAT

- Key word seperti IF , THEN, CASE, LOOP, FOR

- Exception Level seperti DEBUG, LOG, INFO

- Trigger Procedure Variables seperti NEW, OLD, TG_NAME, TG_WHEN

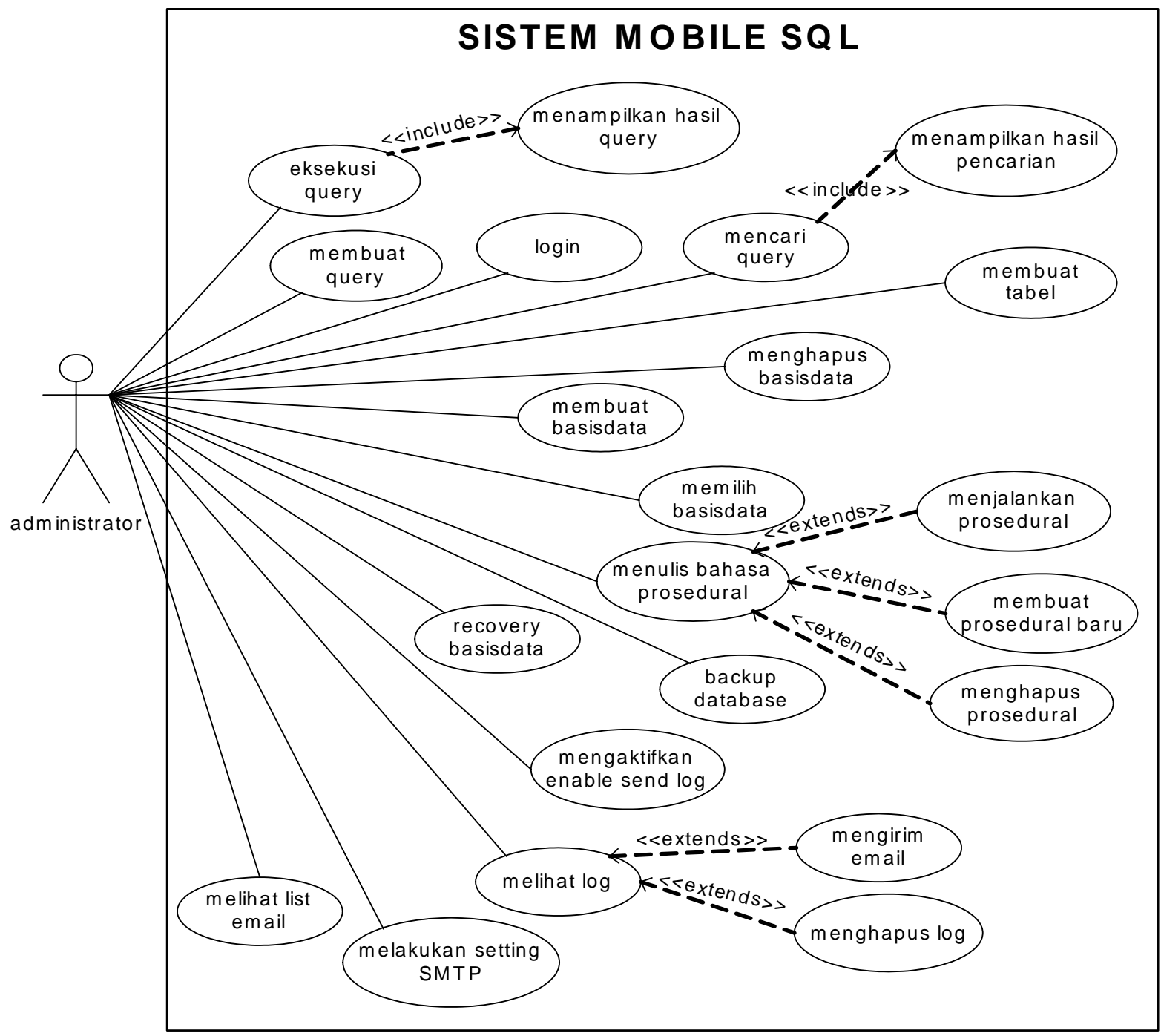

Gambar 1. Use Case Diagram 
Fungsi lain adalah pemberian line number dan highlight pada kode fungsi diatas. Seorang administrator dapat menjalankan prosedural, membuat file baru, membuka file, dan menyimpan file.

5. Backup dan Recovery

Fitur ini digunakan untuk melakukan backup dan recovery basisdata.

6. Preference

Pada Preference ini, user dapat mengaktifkan Enable send log. Fungsi enable send log adalah: mengirim informasi log melalui email kepada administrator (lain) secara langsung apabila ada pengguna yang melakukan administrasi basisdata, membuat daftar email administrator lain, mengirim log melalui email kepada administrator lain, membersihkan log yang ada pada memori telepon seluler, dan melakukan setting SMTP (Simple Mail Transfer Protocol).

\section{Desain Aplikasi}

Gambar 1 menunjukkan use case diagram yang menggambarkan fitur-fitur diatas. Use Case Mobile $S Q L$ terdiri dari satu aktor yaitu administrator basisdata. Seorang administator basisdata dapat melakukan beberapa fungsi utama seperti menjalankan query, membuat basisdata, membuat table, membuat user, menulis bahasa prosedural, melakukan backup dan recovery basisdata. Untuk melihat hasil query, administrator harus menjalankan query terlebih dahulu. Untuk memilih, membuat, atau menghapus basisdata, administrator harus login terlebih dahulu. Status email tergantung pada email yang dikirimkan. "Sukses" untuk email yang berhasil di kirim. "Gagal” untuk email yang tidak berhasil dikirim.
Arsitektur sistem dapat digambarkan seperti diagram pada Gambar 2.

Proses eksekusi query adalah sebagai berikut dalam setiap request [5]:

- Telepon seluler terinstall Mobile SQL mengirimkan data berupa informasi user dan query melalui HTTP request.

- Web server menerima dan melanjutkan data kepada servlet.

- Servlet akan menerima data dari HTTP request sesuai dengan parameter masing-masing.

- Servlet mengakses basisdata PostgreSQL melalui JDBC.

- HTTP response dibuat dalam format XML.

- Mobile SQL melakukan parsing XML dan menampilkan data pada layar telepon seluler.

Salah satu fitur utama dalam Mobile SQL adalah eksekusi query pada fitur Query Tool. Query yang akan dieksekusi dapat dipilih dari query list atau langsung eksekusi query tanpa menyimpan query terlebih dahulu. Eksekusi langsung dapat dilakukan dengan dua cara, pemodelan aktivitas dapat dilihat pada Gambar 3. Pendekatan pertama, pengguna menulis query lalu menjalankan query. Cara kedua adalah menulis query, menyimpan query, kemudian menjalankan query. Bila berhasil maka aplikasi akan ditampilkan hasil query, bila gagal maka aplikasi akan menampilkan alert.

Query yang disimpan akan masuk ke dalam memori telepon seluler. Query yang yang menampilkan informasi seperti SELECT akan ditampilkan pada tampilan telepon seluler. Untuk Query yang tidak menampilkan informasi akan ditampilkan status eksekusi berupa sukses atau gagal. Apabila gagal administrator akan diberitahu error apa yang terjadi.

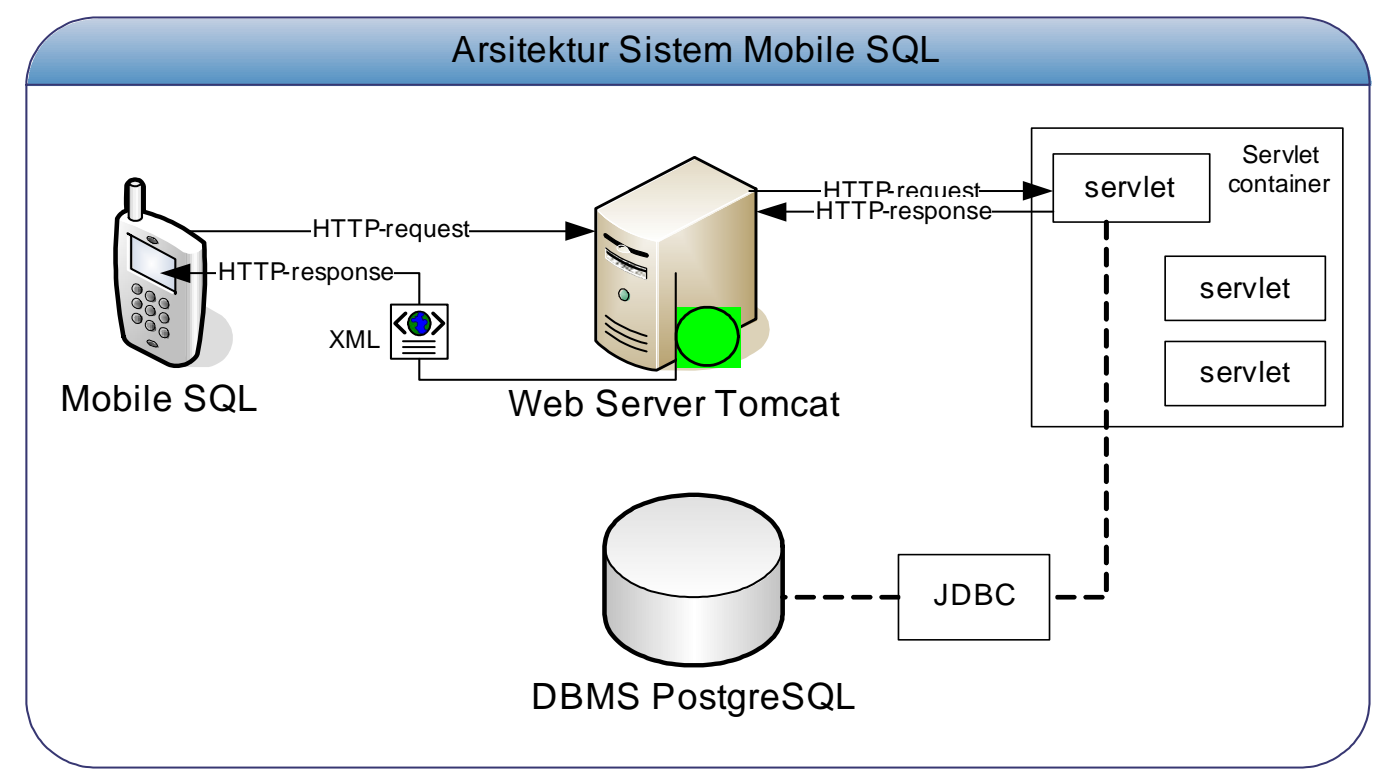

Gambar 2. Arsitektur Sistem 


\section{HASIL IMPLEMENTASI}

Pengembangan aplikasi telah berhasil diujicoba dengan menggunakan Sistem Operasi Microsoft Windows XP, Java Development Kit 1.6, Emulator Wireless Toolkit 2.5.2, Web Server Apache Tomcat 6, dan DBMS PostgreSQL 8.2.
Hasil Implementasi berupa aplikasi MIDlet berekstensi Java Archive (.jar) yang dapat dijalankan pada telepon seluler berbasis java.

Rancangan Use Case pada Gambar 1, diimplementasikan sesuai dengan diagram kelas pada Gambar 4.

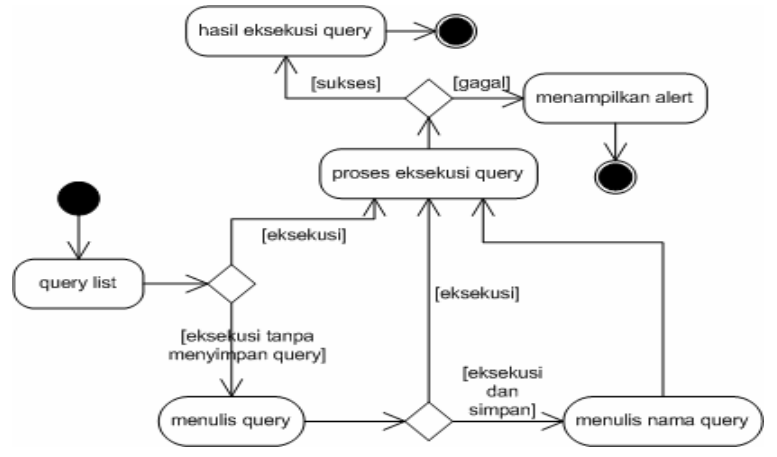

Gambar 3. Activity Diagram pada Eksekusi Query
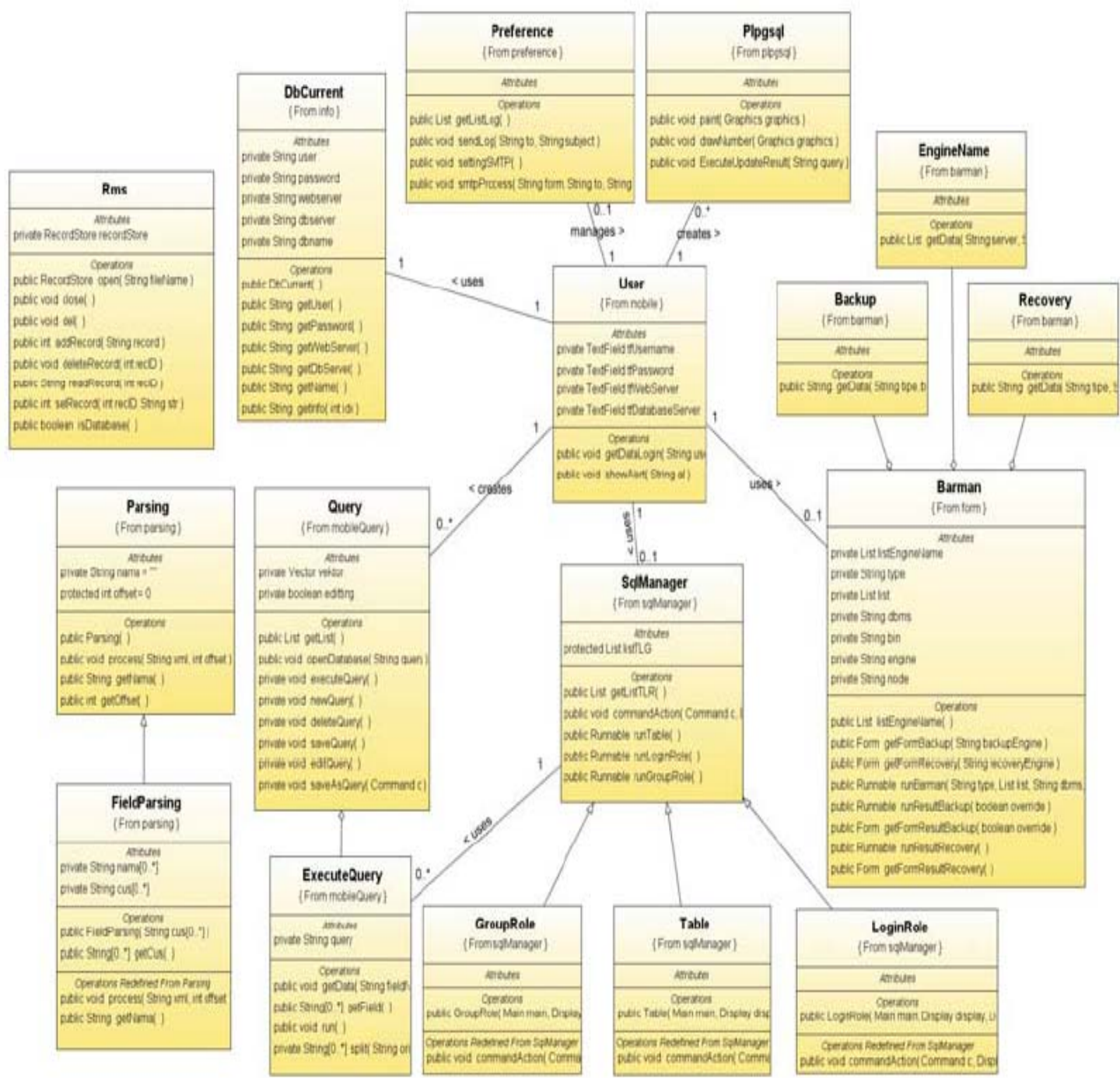

Gambar 4. Kelas Diagram Implementasi 
Penjelasan singkat untuk setiap kelas adalah sebagai berikut:

\begin{tabular}{ll}
\hline Nama Kelas & Deskripsi Singkat \\
\hline RMS & $\begin{array}{l}\text { Kelas untuk mengelola record dalam } \\
\text { sebuah tabel pada basisdata. }\end{array}$ \\
DbCurrent & $\begin{array}{l}\text { Menyediakan informasi mengenai } \\
\text { basisdata yang sedang digunakan/ } \\
\text { aktif. }\end{array}$ \\
User & $\begin{array}{l}\text { Kelas untuk mengelola dan validasi } \\
\text { pengguna aplikasi Mobile SQL dan } \\
\text { database. }\end{array}$ \\
Kuery & $\begin{array}{l}\text { Kelas untuk mengelola query yang } \\
\text { teran }\end{array}$
\end{tabular}

ExecuteQuery Kelas untuk memberikan hasil eksekusi query.

SQLManager Kelas untuk menampilkan daftar tabel, role dan login role.

Table Kelas untuk menambahkan tabel pada server basisdata.

LoginRole Kelas untuk menambahkan login role pada server basisdata.

GroupRole Kelas untuk menambahkan group role pada server basisdata.

Barman Kelas untuk eksekusi backup dan recovery.

Recovery Kelas untuk mengirim parameter recovery ke dalam web server.

Backup Kelas untuk mengirim parameter backup ke dalam web server.

Engine Kelas untuk mengirim parameter engine backup dan recovery Postgre $S Q L$ ke dalam web server.

Plpgsql Kelas editor dan eksekusi bahasa prosedural PL/pqSQL.

Preference Kelas yang bertanggung jawab untuk koneksi ke dalam SMTP server, daftar email dan log.

Parsing Kelas untuk melakukan parsing XML dari informasi sebagai hasil eksekusi query.

Gambar 5 (kiri) adalah tampilan eksekusi query pada fitur Query Tool. Hasil query dapat berupa tampilan tabel atau hanya hasil berupa sukses atau gagal. Hasil query ditampilkan dalam bentuk tabel dan dapat diatur sehingga memudahkan administrator untuk melihat melalui scrolling, pergerakan kiri, kanan, atas dan bawah.

Tampilan eksekusi query sebenarnya adalah hasil parsing perubahan record yang terjadi dan dijadikan sebagai file xml oleh servlet. File xml dapat dilihat pada Gambar 5 (kanan).

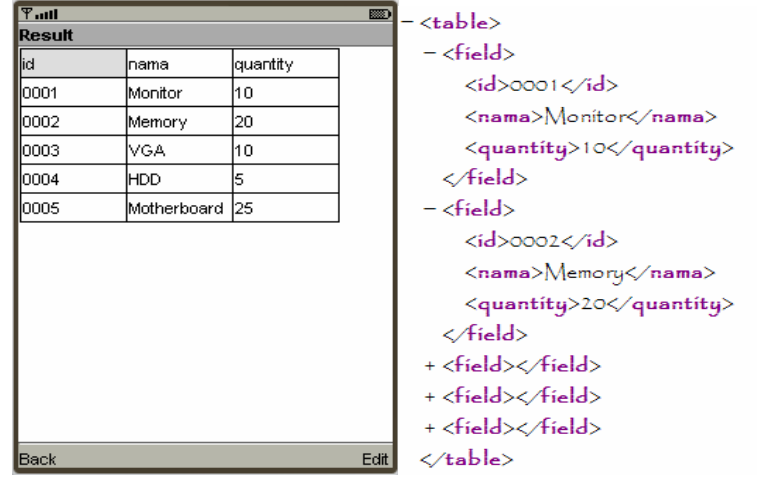

Gambar 5. Hasil Eksekusi Query
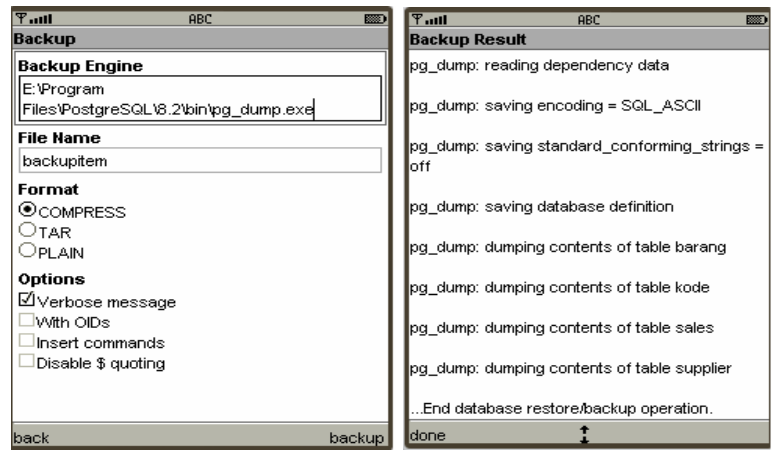

Gambar 6. Melakukan Backup

Dalam melakukan backup ada beberapa hal yang harus di perhatikan diantaranya adalah BackupEngine dan FileName. Walaupun BackupEngine telah ditentukan sebelumnya oleh user namun user tetap dapat menggantinya. FileName tidak perlu diberikan extensions karena aplikasi akan memberikan extensions sesuai dengan format backup.

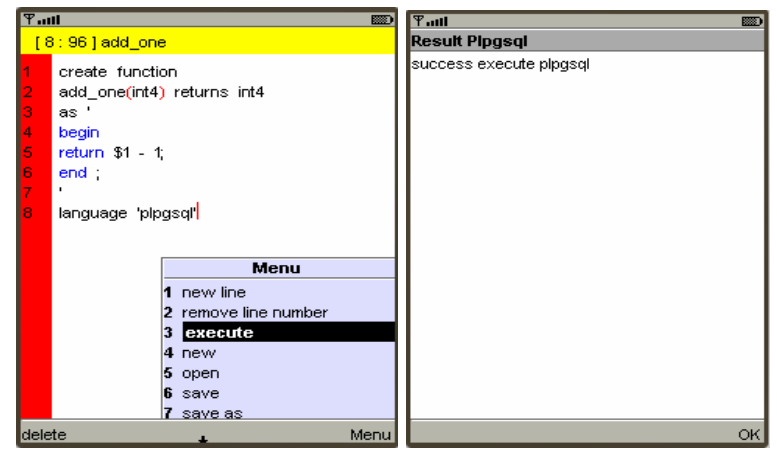

\section{Gambar 7. Menulis Bahasa Prosedural}

Gambar 7 menunjukkan tampilan text editor ketika menulis bahasa prosedural. Bila berhasil dijalankan akan menampilkan pesan sukses.

\section{PENGUJIAN APLIKASI}

Pengujian aplikasi dilakukan dengan dua cara, yaitu untuk uji fungsionalitas terhadap fitur dan pengujian unit untuk alur program. 


\section{Pengujian Fungsionalitas}

Pengujian fungsionalitas dilakukan untuk setiap fitur yang terdapat dalam Mobile SQL dengan menggunakan emulator dan perangkat telepon selular sehingga penguji tidak perlu mengetahui struktur program. Sebuah fitur program dinyatakan lulus uji apabila data keluaran yang dihasilkan dari skenario pengujian sesuai harapan tanpa melihat bagaimana proses untuk mendapatkan keluaran tersebut.

Tabel 1 adalah contoh hasil pengujian untuk fitur Login.

Tabel 1. Hasil pengujian fitur login

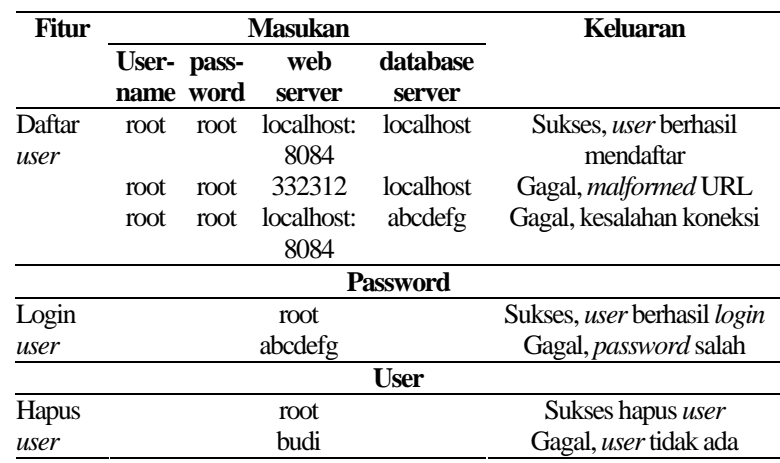

Tabel 2 menjelaskan perbandingan uji fungsionalitas menggunakan telepon seluler dan emulator.

Tabel 2. Perbandingan uji coba fungsionalitas

\begin{tabular}{|c|c|c|}
\hline & Telepon Seluler & Emulator \\
\hline Perangkat & Motorola L-6 & Emulator Wireless Toolkit \\
\hline Pengujian & & 2.5 .2 \\
\hline Memori & $\begin{array}{l}\text { Relative lebih kecil, untuk } \\
\text { pengujian digunakan } \\
\text { memori } 5 \mathrm{MB} \text {. }\end{array}$ & $\begin{array}{l}\text { Sesuai dengan memori } \\
\text { komputer }\end{array}$ \\
\hline Maksimal record & $\begin{array}{l}\text { Menangani maksimal } 160 \\
\text { record }\end{array}$ & $\begin{array}{l}\text { Menangani maksimal } 1000 \\
\text { record }\end{array}$ \\
\hline $\begin{array}{l}\text { Pengiriman dan } \\
\text { penerimaan data }\end{array}$ & Lebih lambat & Sangat cepat \\
\hline Koneksi HTTP & $\begin{array}{l}\text { Koneksi yang tidak ditutup } \\
\text { menyebabkan error }\end{array}$ & $\begin{array}{l}\text { Koneksi yang tidak ditutup } \\
\text { tidak menyebabkan error }\end{array}$ \\
\hline
\end{tabular}

\section{Pengujian Unit}

Uji unit dilakukan dengan membuat skenario pengujian dengan perangkat JMUnit (Java Mobile Unit). Untuk pengujian unit, penguji harus mengetahui struktur program karena menggunakan method yang merupakan bagian terkecil dari program berorientasi obyek. Pada Gambar 8, ditampilkan hasil pengujian dengan JMUnit untuk kelas RMS yang di dalamnya memiliki 8 method, dengan hasil 7 sesuai harapan, dan satu tidak.

Tabel 3 adalah contoh hasil pengujian terhadap kelas RMS, yang dipakai untuk mengelola record dalam memori perangkat telepon selular.
Tabel 3. Hasil pengujian kelas RMS

\begin{tabular}{|c|c|c|c|}
\hline \multirow{2}{*}{$\begin{array}{l}\text { Testing Method } \\
\text { addRecord(String } \\
\text { record):int }\end{array}$} & Parameter & Expected Result & Result \\
\hline & $\begin{array}{l}\text { "root } 1 / 2 \text { root } 1 / 4 \\
\text { localhost: } 8084 \\
\text { »localhost" }\end{array}$ & 1 & 1 \\
\hline \multirow{3}{*}{$\begin{array}{l}\text { setRecord(int } \\
\text { recordId, String } \\
\text { str):boolean } \\
\text { isDatabase():boolean } \\
\text { readRecord(int } \\
\text { recordId):String }\end{array}$} & $\begin{array}{l}\text { 1, "root } 1 / 2 \text { root } 1 / 4 \\
\text { localhost: } 8084 \\
\text { »localhost" }\end{array}$ & True & True \\
\hline & - & True & True \\
\hline & 1 & $\begin{array}{l}\text { erick1/2erick } 1 / 4 \\
\text { localhost:8084 } \\
\text { »localhost }\end{array}$ & $\begin{array}{l}\text { erick } 1 / 2 \text { erick } 1 / 4 \\
\text { localhost:8084 } \\
\text { »localhost }\end{array}$ \\
\hline \multirow{6}{*}{$\begin{array}{l}\text { deleteRecord(int } \\
\text { recordId):void } \\
\text { del():void } \\
\text { open(String } \\
\text { fileName):RecordSto } \\
\text { re }\end{array}$} & 1 & “deleted” & “deleted” \\
\hline & & “delete record” & “delete record” \\
\hline & "dbuser" & javax.microedition. & .javax.microeditio \\
\hline & & & n.rms. \\
\hline & & RecordStore@f82 & RecordStore@f8 \\
\hline & & 8ed68 & 28ed68 \\
\hline close():void & - & $\begin{array}{l}\text { “close record } \\
\text { store” }\end{array}$ & $\begin{array}{l}\text { "ERROR: } \\
\text { RecordStore not } \\
\text { open” }\end{array}$ \\
\hline \multirow[t]{2}{*}{ P..1Il } & \multirow{2}{*}{\multicolumn{2}{|c|}{$\begin{array}{c}\text { JMUnit } 1.0 \\
\text { Default test suite }\end{array}$}} & 숭 핌 \\
\hline & & & \\
\hline $\mathbf{P a}$ & 5s: & 7 & \\
\hline Fai & & 1 & \\
\hline Err & or: & 0 & \\
\hline Tot & tal: & $\mathbf{8}$ & \\
\hline Tim & 1e: & $46 \mathrm{~ms}$ & \\
\hline Exit & & & Test \\
\hline
\end{tabular}

Gambar 8. Pengujian JMUnit Terhadap Kelas RMS

\section{KESIMPULAN DAN SARAN}

Setelah melakukan pengujian terhadap metode white box (dengan JMUnit) dan black box, penulis menarik beberapa kesimpulan antara lain:

1. Administrator dapat melakukan maintenance basisdata melalui aplikasi bergerak dalam bentuk telepon genggam.

2. Administrator dapat mengetahui perubahan yang terjadi di server basisdata melalui email.

3. Aplikasi dapat digunakan untuk menulis bahasa prosedural.

4. Aplikasi berukuran $125 \mathrm{~KB}$, berjalan dengan baik pada ponsel java-enable dengan spesifikasi MIDP 2.0 dan CLDC 1.1.

5. Aplikasi menangani record dengan maksimal 160 record. Keterbatasan ini dipengaruhi oleh memori telepon seluler yang hanya $5 \mathrm{MB}$.

6. Fitur backup dan recovery memiliki kekurangan yaitu lokasi file backup tidak dapat di-explore dan harus ditentukan oleh pengguna. Hal ini disebabkan terutama karena keterbatasan bandwidth pada saat akses ke dalam server. 
Beberapa pengembangan aplikasi yang perlu dilakukan di masa yang akan datang antara lain:

1. Aplikasi mendukung beberapa DBMS sehingga jangkauan penguna menjadi lebih luas.

2. Pengembangan fitur searching yang lebih kompleks sehingga hasil pencarian lebih akurat mengingat jumlah data yang dapat meningkat terus menerus.

3. Meningkatkan keamanan proses pengiriman dan penerimaan data antara telepon seluler dan web server. Hal ini diperlukan mengingat data-data penting basisdata.

\section{DAFTAR PUSTAKA}

1. Sallahudin, M. dan Rosa, A.S. 2006. Pemrograman J2ME: Belajar Cepat Pemrograman Perangkat Telekomunikasi Mobile. Bandung: Informatika.
2. Mardiono, T. 2006. Membangun Solusi Mobile Business dengan Java. Jakarta: PT Elex Media Komputindo.

3. Knudsen, J. 2003. Wireless Java Developing with J2ME, Second Edition. Akses terakhir 13 Maret 2007, dari http://knowfree.net/.

4. Matthew, N. dan Stone, R. 2005. Beginning Databases with PostgreSQL From Novice to Professional, Second Edition. Apress. Akses terakhir 24 Juni 2007, dari http://www.pdfchm. $\mathrm{com} /$.

5. Jendrock, E., Ball, J., Carson, D., Evans, I., Fordin, S., dan Haase, K. 2006. The JavaTM EE 5 Tutorial, Third Edition: For Sun Java System Application Server Platform Edition 9. Addison Wesley Professional. Akses terakhir 25 Oktober 2007, dari http://www.itstudy8.org/. 